\title{
BMI open Child malnutrition and recurrent flooding in rural eastern India: a community-based survey
}

\author{
Jose Manuel Rodriguez-Llanes, ${ }^{1}$ Shisir Ranjan-Dash, ${ }^{2}$ Olivier Degomme, ${ }^{1}$ \\ Alok Mukhopadhyay, ${ }^{2}$ Debarati Guha-Sapir ${ }^{1}$
}

To cite: Rodriguez-Llanes JM, Ranjan-Dash S, Degomme 0, et al. Child malnutrition and recurrent flooding in rural eastern India: a community-based survey. BMJ Open 2011;1: e000109. doi:10.1136/ bmjopen-2011-000109

- Prepublication history and additional tables for this paper are available online. To view these files please visit the journal online (http:// bmjopen.bmj.com).

Received 25 February 2011 Accepted 9 August 2011

This final article is available for use under the terms of the Creative Commons Attribution Non-Commercial 2.0 Licence; see http://bmjopen.bmj.com

${ }^{1}$ CRED-Centre for Research on the Epidemiology of Disasters, Institute of Health and Society, Université catholique de Louvain, Brussels, Belgium

${ }^{2}$ Voluntary Health Association of India, New Delhi, India

Correspondence to Jose Manuel Rodriguez-Llanes; jose. rodriguez@uclouvain.be

\begin{abstract}
Objectives: This study aims to improve the understanding of the relationship between exposure to floods and malnutrition in children aged 6-59 months in rural India. Research has focused exclusively on Bangladeshi children, and few controlled epidemiological studies are available.
\end{abstract}

Method: A community-based cross-sectional study of child nutritional status was carried out in 14 flooded and 18 non-flooded villages of Jagatsinghpur district (Orissa) within one month of the September 2008 floods, and similarly affected by flooding in August 2006. Face-to-face interviews were conducted in 757 households in the flooded villages and 816 in the nonflooded communities. Data used in this study were from those households with children aged 6-59 months. In total, 191 and 161 children were measured, respectively. The association between various malnutrition indicators and the exposure to floods was assessed by univariate and multivariate logistic regression.

Results: Adjusted analyses revealed that children in flooded households were more likely stunted compared with those in non-flooded ones (adjusted prevalence ratio $1.60 ; 95 \% \mathrm{Cl} 1.05$ to 2.44 ). The prevalence of underweight was also higher in children living in the flooded communities (adjusted prevalence ratio $1.86 ; 95 \% \mathrm{Cl} 1.04$ to 3.30 ). Further analyses found that the 26-36-month flooded cohort, thus those children younger than 1 year during the precedent flood in August 2006, attained the largest difference in levels of stunting compared with the unexposed group of the same age.

Conclusion: Exposure to floods is associated with long-term malnutrition in these rural communities of Orissa, India. Children exposed to floods during their first year of life presented higher levels of chronic malnutrition. Long-term malnutrition prevention programmes after floods should be implemented in flood-prone areas.

\section{INTRODUCTION}

Floods are the most common reported natural disaster worldwide, ${ }^{1}$ with an important impact on the health of human populations. $^{2} \quad{ }^{3}$ Their effects are especially

\section{ARTICLE SUMMARY}

\section{Article focus \\ - Study of the connection between flood exposure and childhood malnutrition in rural communities of North Eastern India.}

Key messages

- This is the first study to address the health impacts of floods on child malnutrition in India, a country prone to multiple natural disasters.

- Climate-related extreme events are projected to increase partly induced by climate change, leading to a higher burden of disaster-related diseases.

- Exposure to floods is associated with chronic growth retardation in Indian children, especially in those exposed at very early stages in life.

Strengths and limitations of this study

- The study had high and consistent survey response rates across flooded and non-flooded communities.

- A standard methodology was used, including high-precision WHO standards to assess malnutrition.

- The study does not establish a causal relationship but an association between floods and childhood malnutrition.

- The study is only representative of the children aged 6-59 months living in 29 rural communities.

dramatic in developing countries of South and South-East Asia. ${ }^{4}$ Epidemiological studies in low-income rural areas show evidence for increased risk of disease associated with flooding, such as diarrhoea, ${ }^{5} 6$ cholera, ${ }^{7}$ respiratory infection, ${ }^{5}$ leptospirosis $^{8}$ or post-traumatic stress disorder. ${ }^{9}$ However, little and geographically restricted evidence is available on the nutritional impacts of floods on children. ${ }^{10-13}$

Flooding has been shown to have serious impacts on crop productivity in the past, ${ }^{14} 15$ and the projected higher global temperatures may have non-linear and increasingly negative impacts on existing agricultural 
activities, ${ }^{16}$ particularly on vulnerable countries of south Asia and southern Africa where insufficient adaptation measures are planned. ${ }^{17}$ Crop-yield variation induced by climate change has been suggested as one of the potential mechanisms leading to malnutrition. ${ }^{18}$

This is particularly worrying, since children are especially vulnerable to environmental adversities because of their greater exposure, greater sensitivity to certain exposures and dependence on care givers. ${ }^{19}{ }^{20}$ For this reason, increased weather variability predicted by climatic models is expected to lead to a rise in the health risks of this age group, associated with more frequent extremes such as droughts and floods. ${ }^{19-21}$

The deleterious consequences of poor nutrition are well recognised. Undernutrition is a primary cause of ill health and premature mortality among children in developing countries. ${ }^{22}$ Therefore, malnutrition affects children during the critical phases of their early cognitive, social, motor and emotional development, and has been associated with poor school performance. ${ }^{23} 24$ Poverty and food security are also risk factors which have been found to be associated with poor early development in children. ${ }^{25}$ Thus, these disadvantaged children are less likely to become productive adults, ${ }^{23}$ perpetuating the cycle of poor human development. ${ }^{25}$

India is one of the most disaster-prone countries in the world. ${ }^{1}$ The Indian state of Orissa, located by the Bay of Bengal, is vulnerable to multiple disasters, such as tropical cyclones, storm surges, floods and tsunamis. The state of Orissa suffered a heavy loss of life and property during the cyclone Paradip that hit the state in October $1999 .^{26}$ As a consequence, an autonomous relief and coordination body was created in the state, the Orissa State Disaster Mitigation Authority (OSDMA). Since then, this agency has been actively working in disaster management, prevention, risk reduction and relief activities. Complementary to long-term poverty-alleviation programmes, there are also short-term food-aid governmental programmes to help the victims of disasters within the country (SRD, personal communication).

Despite a rising awareness on understanding the health effects of extreme weather events, ${ }^{19} 2728$ without a better understanding of the mechanisms which produce and maintain high levels of malnutrition in developing countries, policy makers lack crucial information to design specific and effective intervention plans to reduce its prevalence among children. This is especially critical in the face of the foreseen long-lasting intensification of the water cycle ${ }^{29}$ and the rise of human vulnerability to extreme weather events. ${ }^{30}$ In Orissa, climate models predict an intensification of precipitation events, including monsoons, and increased sea-level pressure by the end of the 21st century. ${ }^{31}$ Additionally, vulnerability-resilience analysis shows Orissa as one of the most vulnerable Indian states to climate change. ${ }^{32}$

The most recent floods occurring in Orissa in September 2008 provided an opportunity to explore the strengths of association between flooding and the prevalence of undernutrition while taking other variables that directly affect nutrition into account.

\section{MATERIALS AND METHODS}

This study used a cross-sectional stratified (by village) design with sampling at the household level to collect data on a representative sample of the children aged 6-59 months living in 13 flooded communities and 16 nearby non-flooded villages within a month after the September 2008 floods. We used anthropometric measurements to assess child malnutrition and faceto-face interviews to investigate the exposure to floods as a risk factor for malnutrition and the potential confounding effect of social, health and economic variables.

\section{Study area}

The study site was Jagatsinghpur, a coastal district located in the state of Orissa, eastern India. The district is organised into eight blocks and has a population of 1057629 , with $90 \%$ residing in rural areas. ${ }^{33}$ The district has been severely hit by five major floods in the last decade, the one following the cyclone Paradip (05B) in 1999, followed by heavy floods in 2001, 2003 and 2006. The last floods, starting in mid-September 2008, produced great devastation. ${ }^{1}$

\section{Sample selection}

The villages in this study were selected from the five worst-affected blocks in the district (Kujanga, Biridi, Balikuda, Tirtol and Ersama) according to OSDMA. This agency provided the list of the flooded and non-flooded villages, defined as those with all households inundated by the floods and those with none of the households flooded, respectively. Logistic considerations limited our study to 14 accessible flooded villages. Eighteen nonflooded nearby villages of similar size and demographic characteristics were selected as a comparison group (table S1). These 14 and 18 villages were also inundated and non-inundated, respectively, during previous floods occurring in August 2006. We validated this information using the survey household data. All respondents interviewed in the 14 flooded villages $(n=757)$ confirmed that their households were exposed to only these two floods and the cyclone Paradip in October 1999. Most respondents considered the 2008 floods 'very severe' $(84.6 \%)$ in contrast with the 2006 floods which most households categorised as 'mild' $(79.5 \%)$.

Stratified sampling at the village level was used. In each village, $10 \%$ of households were surveyed (figure 1). This allowed us to obtain a sample with a distribution of households across villages comparable with that in the population. The list of the children aged 6-59 months was obtained at the Integrated Child Development Scheme centre at each village and were used as a check of the information given by the head of the households. In total, 757 households were surveyed in the 14 flooded communities and 816 in the 18 non-flooded villages. In 
Figure 1 Flow diagram of the sample obtained on 352 children aged 6-59 months in Jagatsinghpur district, Orissa, India.

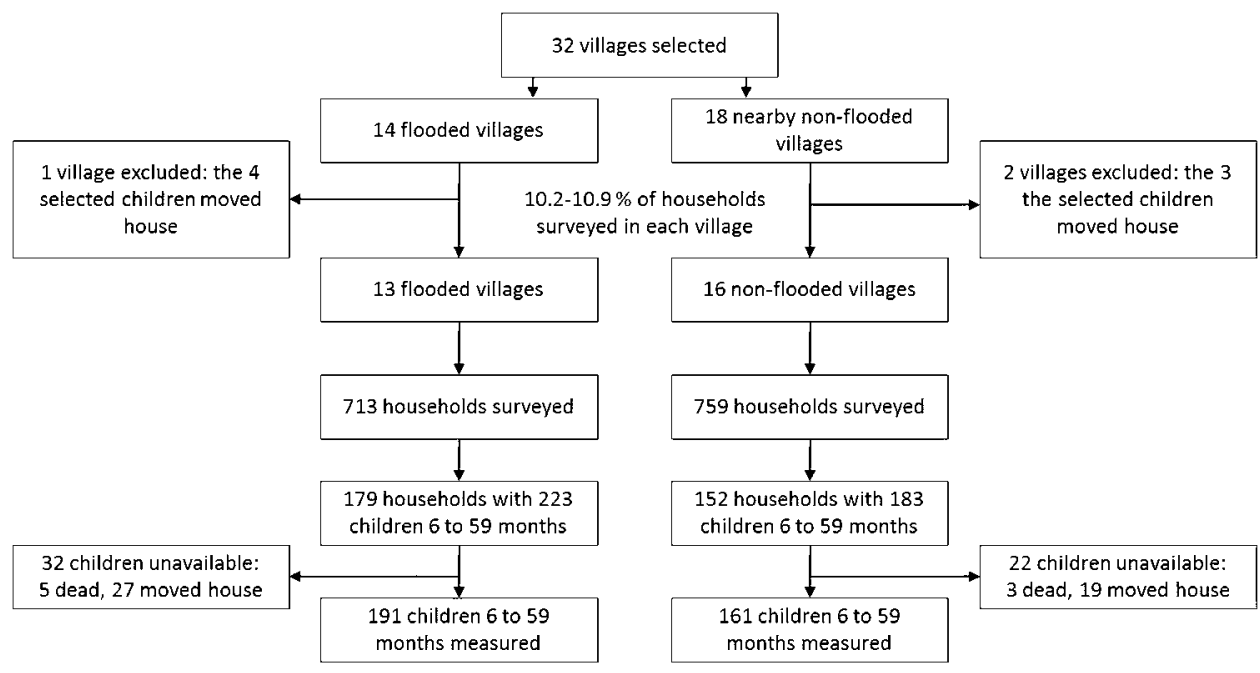

surveyed households with more than one child 6-59 months, all eligible children were selected. In three small villages, one flooded and two non-flooded, all seven eligible children selected moved home, and consequently these villages were excluded from further analyses (figure 1). The study population was defined as those children aged 6-59 months from the remaining 29 villages, which represented $<5 \%$ of the total population and were present overall in less than $25 \%$ of the households surveyed (table S1).

A household was defined as a group of people who usually live under the same roof and share a common kitchen. If an adult member or any eligible children 6-59 months was not at home at the time of the survey, the interviewers returned to the household later. The maximum number of visits per household was fixed at three. For selection of the households, we used a modified EPI 'random walk' method. ${ }^{34}$ At the centre of the village, a team member spun a pen, following the direction pointed by the pen up to the limit of the village. The same procedure was repeated from the new location to randomly choose a direction in which to conduct the survey. A random direction was selected each time a bifurcation was encountered. Random numbers were generated to select the households. The nested data used in this study were from those households with children aged 6-59 months. Thus, the final sample comprised 179 households with 223 children in the 13 flooded villages, and 152 households with 183 children in the 16 non-flooded communities. Overall, $85.2 \%$ of these eligible children were measured and their parents interviewed. The response rate was consistent across the flooded (84\%) and non-flooded communities $(86.6 \%)$. Thirty-two children were not measured in the flooded households. Five of them have recently died, and 27 stayed with relatives in different villages. In the non-flooded communities, 22 children were unavailable. Nineteen of these children moved with their parents elsewhere, and the other three died (figure 1).
Instruments, training and pilot testing

Anthropometric measurements of children and adapted questionnaires were used to obtain the information on anthropometrics, household characteristics and other children variables. Fourteen interviewers, three supervisors and one data manager were specifically trained for this study during a 3-day workshop organised by the Voluntary Health Association of India (VHAI) under the supervision of the MICRODIS (DISaster studies at the MICRO level) project university partners, local government officers and other local researchers. The questionnaires were pretested in 45 households. The questionnaire was translated to the local language in Orissa (Oriya) and then back-translated into English by two different translators. Fieldwork was carried out between 6 October and 19 November 2008.

The weight and height of every child were measured twice to minimise measurement errors and increase precision by using their average value. Weight measurements were undertaken to the nearest $100 \mathrm{~g}$ using a $10 \mathrm{~kg}$ beam balance (Raman Surgical Co., Delhi-33, India) and a $50 \mathrm{~kg}$ standard electronic balance. For children younger than 2 years of age, length was measured to the nearest millimetre in the recumbent position using an infantometer (Narang Medical, Delhi-110 028, India). Children older than 2 years were measured in a standing position using a measuring board. All instruments were calibrated daily.

\section{Outcome measures, exposure and confounders}

The outcomes of this study were three anthropometric indices, stunting (height-for-age), underweight (weightfor-age) and wasting (weight-for-height). Stunting is an indicator of chronic malnutrition, whereas wasting often assesses acute nutritional stress within a population. Underweight combines the previous two, widely used for its operational value. The new WHO standard, was used to calculate the $\mathrm{z}$ scores for these indicators. Malnutrition was a binary variable indicating whether a children is malnourished, $\mathrm{z}$ score $<-2(1)$ or not $(0)$ at the time 
Table 1 Characteristics of 294 households and 352 children in 29 study villages in Orissa, India*

\begin{tabular}{|c|c|c|}
\hline Characteristics & $\begin{array}{l}\text { Flooded } \\
(n=13)\end{array}$ & $\begin{array}{l}\text { Non-flooded } \\
(n=16)\end{array}$ \\
\hline \multicolumn{3}{|l|}{ Household variables } \\
\hline $\begin{array}{l}\text { No of households with } \\
\text { any children } 6-59 \text { months } \\
\text { measured }\end{array}$ & 158 & 136 \\
\hline $\begin{array}{l}\text { Total no of persons residing } \\
\text { in household, mean (SD) }\end{array}$ & $7.2(2.8)$ & $7.5(2.9)$ \\
\hline \multicolumn{3}{|c|}{ No of children younger than 5 years } \\
\hline 1 & $116(73.9)$ & $97(71.3)$ \\
\hline$\geq 2$ & $41(26.1)$ & $39(28.7)$ \\
\hline \multicolumn{3}{|l|}{ Occupation } \\
\hline Not working & $14(8.9)$ & $16(11.8)$ \\
\hline Non-manual & $29(18.4)$ & $16(11.8)$ \\
\hline Agricultural & $50(31.6)$ & $55(40.4)$ \\
\hline Manual & $65(41.1)$ & 49 (36.0) \\
\hline \multicolumn{3}{|l|}{ Religion } \\
\hline Hindu & $114(72.2)$ & $135(99.3)$ \\
\hline Muslim & $44(27.8)$ & $1(0.7)$ \\
\hline \multicolumn{3}{|l|}{ Caste } \\
\hline Scheduled caste & $33(21.9)$ & $17(12.1)$ \\
\hline Other backward class & $38(25.2)$ & $81(57.4)$ \\
\hline General class & $36(23.8)$ & $42(29.8)$ \\
\hline Other & $44(29.1)$ & $1(0.7)$ \\
\hline \multicolumn{3}{|c|}{ Annual income, 1000 Indian rupees } \\
\hline$\leq 3$ & $18(11.5)$ & $16(11.8)$ \\
\hline$>3-6$ & $63(40.1)$ & 67 (49.3) \\
\hline$>6-9$ & $24(15.3)$ & $30(22.1)$ \\
\hline$>9$ & $52(33.1)$ & $23(16.9)$ \\
\hline \multicolumn{3}{|c|}{ Source of drinking-water (at the time of the interview) } \\
\hline Tap in house & $1(0.6)$ & $7(5.1)$ \\
\hline Tube well & $103(65.2)$ & $111(81.6)$ \\
\hline Communal tap & $2(1.3)$ & $8(5.9)$ \\
\hline Protected dug well & $1(0.6)$ & $10(7.4)$ \\
\hline Surface water & $51(32.3)$ & $0(0)$ \\
\hline \multicolumn{3}{|l|}{ Storage of cooked food } \\
\hline Open container & $15(9.5)$ & $14(10.4)$ \\
\hline Closed container & $140(88.6)$ & $119(88.1)$ \\
\hline Refrigerator & $3(1.9)$ & $2(1.5)$ \\
\hline \multicolumn{3}{|l|}{ Child variables } \\
\hline No of children & 191 & 161 \\
\hline 6-59 months measured & & \\
\hline \multicolumn{3}{|l|}{ Height-for-age, no (\%) } \\
\hline Stunting, Z score $<-2$ & $74(38.7)$ & $37(23.0)$ \\
\hline $\begin{array}{l}\text { Severe stunting, } \\
\text { Z score }<-3\end{array}$ & $29(15.2)$ & $14(8.7)$ \\
\hline \multicolumn{3}{|l|}{ Weight-for-age $\dagger$, no (\%) } \\
\hline Underweight, Z score $<-2$ & $40(20.9)$ & $21(13.1)$ \\
\hline $\begin{array}{l}\text { Severe underweight, } \\
\text { Z-score }<-3\end{array}$ & $11(5.8)$ & $7(4.4)$ \\
\hline \multicolumn{3}{|l|}{ Weight-for-height, $\ddagger$ no (\%) } \\
\hline Wasting, Z score $<-2$ & 23 (12.2) & $19(11.9)$ \\
\hline $\begin{array}{l}\text { Severe wasting, } \\
\text { Z score }<-3\end{array}$ & $8(4.3)$ & $8(5.0)$ \\
\hline \multicolumn{3}{|l|}{ Birth weight, kg } \\
\hline$<2.7$ & $87(45.5)$ & $86(53.4)$ \\
\hline
\end{tabular}

Table 1 Continued

\begin{tabular}{lcc}
\hline Characteristics & $\begin{array}{l}\text { Flooded } \\
(\mathbf{n = 1 3 )}\end{array}$ & $\begin{array}{l}\text { Non-flooded } \\
(\mathbf{n = 1 6 )}\end{array}$ \\
\hline $\begin{array}{c}\text { Sex } \\
\quad \text { Female }\end{array}$ & $104(54.5)$ & $75(46.6)$ \\
$\quad$ Male & $81(42.4)$ & $76(47.2)$ \\
Age, months $\S$ & $110(57.6)$ & $85(52.8)$ \\
Immunisation coverage & $30.0(1.0)$ & $32.1(1.1)$ \\
$\quad$ Total & & \\
$\quad$ Partial & $22(11.5)$ & $42(26.1)$ \\
& $169(88.5)$ & $119(73.9)$ \\
\hline
\end{tabular}

*Information for income, household size and number of children younger than 5 years could not be determined in one household of a flooded village. The caste of one household in a flooded village and one household in a non-flooded village could not be determined. The type of storage of cooked food in one household of a non-flooded village could not be obtained. Description of variables is the absolute number of household or children associated with each characteristic (percentage of the total) except where otherwise indicated.

tOne observation with missing data was excluded from the analyses in the non-flooded cohort.

$\ddagger$ Four observations with missing data were excluded from the analyses in the flooded cohort and one in the non-flooded cohort. $\S$ Child age is reported as mean (SE).

१Total immunisation includes children vaccinated, confirmed with vaccination card, against polio (OPV, three doses), tuberculosis (BCG, 1 dose), measles (MCV, 1 dose), hepatitis B (HEPB, three doses), diphtheria and tetanus toxoid and pertussis (DPT, three doses).

of the interview. The fundamental variable of this study was the level of children's exposure to floods, measured as whether the village was flooded (1) or not (0). Therefore, 13 other variables included information at the household and individual (children) level (table 1). In the first group, we recorded the number of persons residing in each household (household size) measured as a continuous variable, number of children younger than 5 years living in a household, dichotomised as one (0) or otherwise (1). The main occupation of the household was recorded in detailed categories and later recoded as non-manual (reference), agricultural, manual and unemployed. Two religions were present in the study area: Hinduism, taken as the reference group, and Muslim. The caste of the household was based on the household head and was grouped as a scheduled caste, other backward class or general class (reference category). The general class represents the higher caste status in India. The scheduled caste is the social group historically subject to the higher deprivation levels in the country. Monthly household income (in 1000 Indian rupees (INR)) was collected from respondents as a continuous variable and recoded into four categories: $\leq 3,>3-6,>6-9$ and $>9$, chosen as the reference category. The household source of drinking-water at the time of the interview was recorded in a detailed questionnaire (table 1) and recoded as whether they were more secure sources, such as wells and taps (0) or unsecure such as surface water (1), consumed in the 
flooded areas. The storage of cooked food was also listed using a detailed questionnaire and dichotomised into closed containers (0) and open containers (1).

Within the second group, a number of individual variables were recorded. Birth weights were obtained from birth certificates and/or vaccination cards available, and were coded as a binary variable above and below the median. Sex was a binary variable. Age was recorded from birth certificates and/or vaccination cards in most cases $(85 \%$ of respondents). If these were not available, local calendars were used. Children were classified by the reported age into the following groups (in months): 6 to 18,18 to 26,26 to 36,36 to 46 and 46 to 59. This classification was used to compare the prevalence of malnutrition in those children younger than 1 year exposed to the 2006 floods (aged 26-36 months at the time of this study), with those of the non-flooded cohort in the same age group. Children's immunisation coverage was obtained from vaccination cards available. Children fully vaccinated, as proved by vaccination card, against polio (three doses), tuberculosis (one dose), measles (one dose), hepatitis $\mathrm{E}$ (three doses), diphtheria and tetanus toxoid, and pertussis (three doses) were classified as those with full immunisation coverage $(0)$, otherwise partially immunised (1).

\section{Power analysis}

Considering that $10 \%$ of 14948 households (7248 flooded and 7700 non-flooded) were planned to be surveyed and that the expectation of getting a household with at least one eligible child is $1 / 4$, the expected number of households containing children in our sample was 181 and 192. Assuming a two-thirds prevalence of malnutrition in non-flooded compared with flooded households, with $\alpha$ (error) $=0.05$, using the average percentage of stunting in Orissa state (children $<5$ years) as the prevalence for the flooded area $(45)^{36}$ and two-thirds (30) as a conservative approximate for the non-flooded, a power of $84 \%$ would be achieved. The minimum sample size, with a power of $80 \%$, would be 164 in each group.

\section{Data analysis}

Malnutrition indices were calculated using ENA for SMART software version November $2008 .{ }^{37}$ The new WHO standard was used to calculate $\mathrm{z}$ scores. Statistical analyses were conducted in $\mathrm{R}$ version 2.10.1 ( $\mathrm{R}$ Development Core Team 2008). ${ }^{38}$ Missing data were rare. Data were missing on underweight and wasting in one and five respondents, respectively. In one respondent, data were missing on income, number of children under five and household size. Data were missing on caste in two respondents, and on food storage in one respondent.

In cross-sectional epidemiological research studying rare outcomes, the OR is very close to the RR. If the outcome is common as is the case in this study (ie, prevalence $>10 \%$ ), ORs tend to differ from RRs. Prevalence ratios (PR), as named in this study, were then used instead of prevalence OR (POR), to avoid confusion in the interpretation of the results. ${ }^{39} 40$ Quasi-binomial models were used to avoid overdispersion. Additionally, starting values and increasing the number of iterations were necessary to fit these models. ${ }^{41}$ GLM quasi-binomial models were used to explore bivariate associations between malnutrition and independent variables, reported as crude (unadjusted) PRs with their associated 95\% CIs. Multivariate (adjusted) models were used to identify variables predictive of malnutrition, controlling for all other variables in the model. ANOVA models were used to test the difference between Z-scores (a continuous variable) of the flooded and non-flooded cohorts in each of the age groups previously defined. Two-way interactions were examined for significant parameters in the adjusted models $(\mathrm{p}<0.05)$. The $\alpha$ level was set at $5 \%$, and all statistical tests were two-sided.

\section{RESULTS}

\section{Demographic characteristics}

Table 1 lists the characteristics of the sample by exposure group. More non-manual (18.4\%) and less agricultural work $(31.6 \%)$ were reported by the respondents in the flooded communities compared with the non-flooded communities $(11.8 \%$ and $40.4 \%$, respectively). The higher proportion of Muslims in the flooded group $(27.8 \%)$ was due to a large Muslim population living in a single village. More individuals from the scheduled caste were living in the flooded communities (21.9\%) compared with the non-flooded $(12.1 \%)$. Access to safe drinking-water was limited right after the floods, and $32.3 \%$ of the respondents confirmed they had drunk surface water.

\section{Child malnutrition}

The overall prevalences of stunting, underweight and wasting were $31.5 \%, 17.4 \%$ and $12.1 \%$, respectively (table 1). However, the prevalence of stunting was $38.7 \%$ in the flooded cohort compared with $23.0 \%$ in the nonflooded cohort. Similarly, the prevalence of underweight was more important in the children living in flooded communities $(20.9 \%)$ compared with those inhabiting non-flooded villages $(13.1 \%)$. Wasting was very similar in children experiencing flooding and those populating non-flooded areas, with $12.2 \%$ and $11.9 \%$, respectively (table 1).

\section{Factors associated with stunting}

Table S2 shows the crude and adjusted associations between stunting and exposure to floods, household size, number of children younger than 5 years, occupation, religion, caste, monthly family income, source of drinking-water, storage of cooked food, childbirth weight, sex, age and immunisation coverage. In the bivariate model, exposure to floods, religion and family income were associated with stunting. Muslim children were at higher risk of being stunted, but this difference did not remain statistically significant in the multivariate model. Table 2 shows the significant determinants of 
Table 2 Factors associated with malnutrition in children aged 6-59 months in 29 study villages in Orissa, India

\begin{tabular}{|c|c|c|c|c|c|c|}
\hline \multirow[b]{2}{*}{ Factor } & \multicolumn{2}{|l|}{ Stunting* $^{*}$} & \multicolumn{2}{|l|}{$\underline{\text { Underweight } †}$} & \multicolumn{2}{|l|}{ Wasting $\neq$} \\
\hline & APR (95\% CI) & p Value & APR $(95 \% \mathrm{CI})$ & p Value & APR (95\% Cl) & p Value \\
\hline \multicolumn{7}{|l|}{ Flood exposure level } \\
\hline $\begin{array}{l}\text { Household in } \\
\text { non-flooded village }\end{array}$ & 1 (reference) & & 1 (reference) & & 1 (reference) & \\
\hline $\begin{array}{l}\text { Household in } \\
\text { flooded village }\end{array}$ & $1.60(1.05$ to 2.44$)$ & 0.031 & $1.86(1.04$ to 3.30$)$ & 0.036 & $1.21(0.61$ to 2.42$)$ & 0.58 \\
\hline \multicolumn{7}{|c|}{ No of children younger than 5 years } \\
\hline 1 & 1 (reference) & & 1 (reference) & & 1 (reference) & \\
\hline$\geq 2$ & $0.91(0.64$ to 1.28$)$ & 0.58 & 1.69 (1.05 to 2.72$)$ & 0.031 & $1.29(0.68$ to 2.45$)$ & 0.43 \\
\hline \multicolumn{7}{|c|}{ Annual income, 1000 Indian rupees } \\
\hline$>9$ & 1 (reference) & & 1 (reference) & & 1 (reference) & \\
\hline$>6-9$ & $1.02(0.58$ to 1.81$)$ & 0.94 & 2.01 (0.89 to 4.54$)$ & 0.095 & $1.27(0.42$ to 3.86$)$ & 0.67 \\
\hline$>3-6$ & $1.20(0.77$ to 1.88$)$ & 0.42 & $1.22(0.57$ to 2.59$)$ & 0.60 & 1.41 (0.56 to 3.54$)$ & 0.47 \\
\hline$\leq 3$ & 1.85 (1.11 to 3.09$)$ & 0.019 & 1.76 (0.78 to 3.99$)$ & 0.18 & $2.13(0.76$ to 6.02$)$ & 0.15 \\
\hline \multicolumn{7}{|l|}{ Birth weight, kg } \\
\hline$\geq 2.7$ & 1 (reference) & & 1 (reference) & & 1 (reference) & \\
\hline$<2.7$ & 1.17 (0.85 to 1.62$)$ & 0.34 & 1.80 (1.11 to 2.92$)$ & 0.017 & $1.28(0.69$ to 2.38$)$ & 0.46 \\
\hline
\end{tabular}

stunting in the adjusted analyses. Children living in flooded households were more likely stunted compared with those living in non-flooded communities (adjusted PR (APR), 1.60; 95\% CI 1.05 to 2.44). The children of the poorest families (those reporting to earn equal to or less than 3000 rupees a year) were also more likely stunted compared with those in the higher income class (APR 1.85; 95\% CI 1.11 to 3.09 ). The interaction between monthly household income and exposure to floods was not significant.

\section{Factors associated with underweight and wasting}

Underweight was associated with the number of children younger than 5 years living in a household, monthly family income and childbirth weight in the univariate analyses (Table S3). Family monthly income was not significant in the multivariate model (APR 1.76; $95 \%$ CI 0.78 to 3.99 ). Contrarily, exposure to floods was not statistically significant in the bivariate model (PR 1.60; $95 \%$ CI 0.98 to 2.59 ), but it became significant in the multivariate model (APR 1.86; $95 \%$ CI 1.04 to 3.30; see tables 2, S3). Therefore, children living in a household with one or more children under 5 presented a higher risk of underweight than those living without other under-5 counterparts (APR 1.69; 95\% CI 1.05 to 2.72). Low-birth-weight children $(<2.7 \mathrm{~kg})$ were at higher risk of being underweight compared with those born with higher weights (APR 1.80; 95\% CI 1.11 to 2.92). The interaction between exposure to floods and low-birth weight and number of under- 5 children were not significant. Wasting was not associated with any of the factors considered in this study either in bivariate or in multivariate models (tables 2, S4).
Malnutrition and recurrent flooding

ANOVA analyses were used to test the differences in Z-scores for stunting and underweight by age category between the flooded and non-flooded cohorts. The children of the flooded cohort aged 26-36 months presented the largest difference in stunting with those of the non-flooded compared with other age groups, except for the 6-18-month cohort (table 3). The difference was only significant for the group 26-36 $(p<0.001)$. These differences were less evident for underweight (see table 3).

\section{DISCUSSION}

Our study represents a first attempt to understand the role of exposure to natural disasters as a risk factor for child malnutrition in India. Within 1 month after the floods, wasting did not differ among children inhabiting the flooded villages and those living in the non-flooded

Table 3 Differences in stunting and underweight $Z$ scores between flooded and non-flooded children by age groups in Orissa, India

\begin{tabular}{|c|c|c|c|c|}
\hline \multirow[b]{2}{*}{ Factor } & \multicolumn{2}{|l|}{ Stunting } & \multicolumn{2}{|c|}{ Underweight } \\
\hline & $\begin{array}{l}\text { Difference } \\
\text { in mean }\end{array}$ & $\begin{array}{l}\mathbf{p} \\
\text { Value }\end{array}$ & $\begin{array}{l}\text { Difference } \\
\text { in mean }\end{array}$ & $\begin{array}{l}\mathbf{p} \\
\text { Value }\end{array}$ \\
\hline
\end{tabular}

Age, months

$\begin{array}{lllrl}>6-18 & -1.1 & 0.17 & -0.3 & 0.39 \\ >18-26 & -0.02 & 0.95 & 0.1 & 0.74 \\ >26-36 & -1.1 & 0.0006 & -0.4 & 0.07 \\ >36-46 & -0.5 & 0.29 & -0.3 & 0.19 \\ >46-60 & -0.2 & 0.62 & -0.3 & 0.38\end{array}$


areas. In contrast, a higher risk of stunting was detected in children living in the flooded areas in bivariate and multivariate models. The risk of underweight was significantly higher only in the adjusted analyses. All villages under study in the flooded group were also inundated in previous floods occurring in August 2006 (25 months earlier). In the absence of other disasters in the area, our results suggest an association of chronic malnutrition and previous flooding in these children. The study also showed that the exposed cohort of children aged $<1$ year during the 2006 floods presented the largest difference in levels of stunting with the nonflooded group of the same age. This finding underlines the importance of early exposure to floods as a risk factor for anthropometric failure in children.

One evident limitation of this study is a direct consequence of its cross-sectional design, which did not allow us to establish causal relationships. Second, this study was conducted soon after waters started to recede in a heavily flooded area where roadblocks were commonplace. As a consequence, there exists selection bias in the choice of the affected villages. Nevertheless, if the situation was even worst in more isolated villages not represented in the sample, it is remarkable that we already found an increased risk for malnutrition among these exposed children. In contrast, wasting could have been more important than reflected in our results in the most isolated communities. Thus, this community-based study limits our findings to two subpopulations of children living in 29 rural communities of Orissa. A population survey would be necessary to assess health impacts and disease risk in a population better representing the one affected, and thus making it easier to design wider interventions. Third, this study did not include other relevant conditions related to malnutrition, such as maternal education, variables on losses, food insecurity and coping mechanisms which may impact this association and further explain the mechanisms which lead to malnutrition after floods. Fourth, a different instrument was used to weigh children heavier than $10 \mathrm{~kg}$, instead of a single balance ${ }^{42}$ Fifth, our power calculations did not take into consideration subgroup analyses. Probably further determinants of malnutrition would have been revealed using a larger sample size. Sixth, self-reported economic status, especially after disasters, can be subject to reporting bias. To minimise false reporting, field researchers informed the respondents about the purpose of the survey and cross-checked the economic information collected with the house type and assets.

The striking similarity in wasting among both groups suggests that the flooded cohort was not subject to additional short-term nutritional stress compared with children living in the non-flooded area, at least immediately after the flood. This is probably associated with the fact that government and NGOs were mobilised rapidly and provided supplies right after the onset of flooding (unpublished data), and this might be the case after the 2006 event. In floods occurring in Bangladesh in 1998, other authors found critical levels of malnutrition (ie, $>15 \%$ ) during the flood period. ${ }^{12}$ The exceptionally long duration and magnitude of that flooding probably played an important role in causing a more dramatic situation than that observed in these communities of Orissa. Further research on the same flood event in Bangladesh using a comparison group failed to detect any effect of floods on wasting 2 months after the floods. ${ }^{13}$ In another study on the same floods, the levels of wasting had decreased considerably 4 months later. ${ }^{12}$ These results suggest that the recovery after floods seems to occur promptly in these populations. On the other hand, the absence of significant wasting in the flooded communities of Orissa together with simultaneous higher levels of underweight and stunting suggest that both reflect the long-term health and nutritional experience of the population. ${ }^{43}$ These results from India are similar to those found in Bangladesh in which the long-term consequences of floods on nutrition are depicted. ${ }^{13}$

Low-income proxies (such as landlessness) have been observed as a risk factor for acute malnutrition among flood-affected children in Bangladesh. ${ }^{10}$ More recently, another study has shown that the children of floodaffected families taking loans at very high rates did not improve their nutritional status compared with those having access to credits at very low or no interest. ${ }^{12}$ However, the latter studies only establish the short-term effects of the disaster. None have established economic status as a risk factor for chronic malnutrition-a long term consequence, among flood-affected children.

Finally, the lack of significant interaction between significant variables, such as exposure to floods and income, supports the hypothesis that higher economic status is not protective against the impacts of floods on child malnutrition, at least in these communities. More research is necessary to understand the complex dynamics of child malnutrition after severe flooding and its socio-economic and health determinants. Representative larger surveys are recommended, which should help to confirm these results and help policy makers implement appropriate measures.

Acknowledgements We would like to acknowledge the MICRODIS consortium for development of tools and conceptual models, as well as the VHAI research and field team for data collection and study design. We are grateful to N Paliakara for her assistance with nutritional aspects of this paper and insightful comments on an earlier version of this manuscript.

Correction notice The "To cite: ..." information and running footer in this article have been updated with the correct volume number (volume 1).

Funding This research was funded by the European FP6 6th Framework Programme under The MICRODIS Project-Integrated Health, Social and Economic Impacts of Extreme Events: Evidence, Methods and Tools (Contract No GOCE-CT-2007-036877).

Competing interests None.

Patient consent Obtained.

Ethics approval Ethics approval was provided by the Community Health Ethics Committee, Voluntary Health Association of India, New Delhi.

Contributors DG-S obtained the funding. DG-S, AM, SR-D, JMR-L conceived and designed the study. SR-D and AM collected the data and supervised the 
study. JMR-L, DG-S, OD analysed and interpreted the data. JMR-L conducted the statistical analyses and drafted the manuscript. SR-D, JMR-L, DG-S and AM provided administrative, technical or material support. All authors critically revised the manuscript for important intellectual content.

Provenance and peer review Not commissioned; externally peer reviewed.

Data sharing statement Statistical code available from the corresponding author.

\section{REFERENCES}

1. EM-DAT: The OFDA/CRED International Disaster Database. Data Version: v12.07. Brussels: Université Catholique de Louvain. http:// www.emdat.be/ (accessed Oct 2009).

2. Noji EK. The Public Health Consequences of Disasters. New York: Oxford University Press, 1997:3-20.

3. Ahern M, Kovats RS, Wilkinson $P$, et al. Global health impacts of floods: epidemiologic evidence. Epidemiol Rev 2005;27:36-46.

4. Rodriguez J, Vos F, Below R, et al. Annual Disaster Statistical Review 2008: The Numbers and Trends. Brussels: Jacoffset Printers, 2009:1-25.

5. Biswas R, Pal D, Mukhopadhyay SP. A community based study on health impact of flood in a vulnerable district of West Bengal. Indian $J$ Public Health 1999;43:89-90.

6. Mondal NC, Biswas R, Manna A. Risk factors of diarrhoea among flood victims: a controlled epidemiological study. Indian J Public Health 2001;45:122-7.

7. Sur D, Dutta P, Nair GB, et al. Severe cholera outbreak following floods in a northern district of West Bengal. Indian J Med Res 2000;112:178-82.

8. Leal-Castellanos CB, García-Suárez R, González-Figueroa E, et al. Risk factors and the prevalence of leptospirosis infection in a rural community of Chiapas, Mexico. Epidemiol Infect 2003;131:1149-56.

9. Liu A, Tan $\mathrm{H}$, Zhou J, et al. An epidemiologic study of posttraumatic stress disorder in flood victims in Hunan China. Can J Psychiatry 2006;51:350-4.

10. Stewart MK, Fauveau V, Chakraborty J, et al. Post-flood nutritional anthropometry of children in Matlab, Bangladesh. Ecol Food Nutr 1990;24:121-31.

11. Choudhury AY, Bhuiya A. Effects of biosocial variables on changes in nutritional status of rural Bangladeshi children, pre- and postmonsoon flooding. J Biosoc Sci 1993;25:351-7.

12. Hossain SM, Kolsteren P. The 1998 flood in Bangladesh: is different targeting needed during emergencies and recovery to tackle malnutrition? Disasters 2003;27:172-84.

13. del Ninno C, Lundberg M. Treading water: the long-term impact of the 1998 flood on nutrition in Bangladesh. Econ Hum Biol 2005;3:67-96.

14. Paul BK, Rasid $\mathrm{H}$. Flood damage to rice crop in Bangladesh. Geogr Rev 1993;83:150-9.

15. Banerjee L. Effect of flood on agricultural wages in Bangladesh: an empirical analysis. World Dev 2007;35:1989-2009.

16. Howden SM, Soussana J, Tubiello FN, et al. Adapting agriculture to climate change. Proc Natl Acad Sci U S A 2007;104:19691-6.

17. Lobell DB, Burke MB, Tebaldi $C$, et al. Prioritizing climate change adaptation needs for food security in 2030. Science 2008;319:607-10.

18. Haines A, Kovats R, Campbell-Lendrum D, et al. Climate change and human health: impacts, vulnerability, and mitigation. Lancet 2006;367:2101-9.

19. Ebi KL, Paulson JA. Climate change and children. Pediatr Clin North Am 2007;54:213-26.

20. Bunyavanich S, Landrigan CP, McMichael AJ, et al. The impact of climate change on child health. Ambul Pediatr 2003;3:44-52.
21. Kistin EJ, Fogarty J, Pokrasso RS, et al. Climate change, water resources and child health. Arch Dis Child 2010;95:545-9.

22. Black RE, Allen LH, Bhutta ZA, et al. Maternal and child undernutrition: global and regional exposures and health consequences. Lancet 2008;371:243-60.

23. Grantham-McGregor S, Cheung YB, Cueto S, et al. Developmenta potential in the first 5 years for children in developing countries. Lancet 2007;369:60-70.

24. Walker SP, Wachs TD, Meeks Gardner J, et al. Child development: risk factors for adverse outcomes in developing countries. Lancet 2007;369:145-57.

25. Chilton M, Chyatte M, Breaux J. The negative effects of poverty and food insecurity on child development. Indian J Med Res 2007;126:262-72.

26. Thomalla F, Schmuck $H$. 'We all knew that a cyclone was coming': disaster preparedness and the cyclone of 1999 in Orissa, India. Disasters 2004;28:373-87.

27. McMichael AJ, Woodruff RE, Hales S. Climate change and human health: present and future risks. Lancet 2006;367:859-69.

28. Cook A, Watson J, Buynder PV, et al. 10th anniversary review: natural disasters and their long-term impacts on the health of communities. J Environ Monit 2008;10:167-75.

29. Huntington TG. Evidence for intensification of the global water cycle: review and synthesis. J Hydrol 2006;319:83-95.

30. Huppert HE, Sparks RSJ. Extreme natural hazards: population growth, globalization and environmental change. Philos Transact $A$ Math Phys Eng Sci 2006;364:1875-88.

31. Solomon S, et al, eds. Climate Change 2007: The Physical Science Basis. Contribution of Working Group I to the Fourth Assessment Report of the Intergovernmental Panel on Climate Change. Cambridge: Cambridge University Press 2007:996.

32. Brenkert AL, Malone EL. Modeling vulnerability and resilience to climate change: a case study of India and Indian states. Clim Change 2005;72:57-102

33. The Census of India. Census-2001 Data Online. New Delhi, India: The Registrar General \& Census Commissioner, Ministry of Home Affairs, Government of India. http://www.censusindia.gov.in/ (accessed Aug 2008).

34. Turner AG, Magnani RJ, Shuaib M. A not quite as quick but much cleaner alternative to the expanded programme on immunization (EPI) cluster survey design. Int J Epidemiol 1996;25:198-203.

35. Milligan P, Njie A, Bennett S. Comparison of two cluster sampling methods for health surveys in developing countries. Int $J$ Epidemiol 2004;33:469-76.

36. International Institute for Population Sciences (IIPS) and Macro International. National Family Health Survey (NFHS-3), 2005-06: India: Volume I. Mumbai: IPPS, 2007:267-313.

37. Emergency Nutrition Assessment (ENA). Software for standardized monitoring and assessment of relief and transitions (SMART), version November 2008. http://www.nutrisurvey.de/ena/ena.html (accessed Nov 2010).

38. R Development Core Team. R: A Language and Environment for Statistical Computing. Vienna: R Foundation for Statistical Computing, 2008. ISBN 3-900051-07-0. http://www.R-project.org

39. Thompson M, Myers J, Kriebel D. Prevalence odds ratio or prevalence ratio in the analysis of cross sectional data: what is to be done? Occup Environ Med 1998;55:272-7.

40. Deddens JA, Petersen MR. Approaches for estimating prevalence ratios. Occup Environ Med 2008;65:501-6.

41. Lumley T. Categorical data regression. In: Couper MP, Kalton G, Rao JNK, et al, eds. Complex Surveys: A Guide to Analysis Using $R$. Hoboken, NJ: John Wiley \& Sons, 2010:109-33.

42. WHO. The Management of Nutrition In Major Emergencies. Geneva: WHO, 2000:1-236.

43. de Onis M, Blössner M. WHO Global Database on Child Growth and Malnutrition. Geneva: WHO, 1997:1-67. 